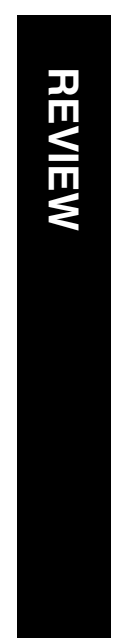

\author{
Research into \\ glaucoma and \\ ethnicity (ReGAE) 4: \\ trabeculectomy for \\ advanced glaucoma: \\ the surgical journey \\ of African- \\ Caribbean patients
}

Centre for Health and Social Care Improvement, University of Wolverhampton, Wolverhampton, UK

Correspondence: V Cross, Centre for Health and Social Care Improvement, University of Wolverhampton, City Campus, Molineux Street, Wolverhampton, Black Country WV1 1SB UK Tel: + 4401902518711 ; Fax: + 4401902518660 . E-mail: vinette.cross@ wlv.ac.uk

Received: 25 September 2007

Accepted in revised form: 19 December 2007 Published online: 18 January 2008

VC and MG designed the study, and interviewed the participants. VC and MG were involved in data analysis and preparation of the paper. SC contributed to the data collection and analysis process. PS conceived and is leader of the Birmingham ReGAE Project and reviewed the final draft. PS is the guarantor.

\begin{abstract}
Aim To explore the experiences of AfricanCaribbean patients with advanced glaucoma. Methods Semi-structured qualitative interviews were used to elicit patients' subjective experiences of becoming a glaucoma patient, receiving treatment, undergoing surgery, and its aftermath. Interview transcripts underwent narrative analysis.

Results The surgeon-patient relationship was central to developing effective coping strategies. Participants described their experiences in terms of what they considered were their responsibilities as patients to the surgeon-patient relationship. They also defined the surgeon's responsibilities and obligations.

Conclusions The use of patient narratives provides a valuable resource for enhancing communication skills and relationshipcentred care in the hospital eye service. Eye (2008) 22, 1456-1458; doi:10.1038/sj.eye.6703095; published online 18 January 2008
\end{abstract}

Keywords: glaucoma; secondary eye care; African-Caribbean; trabeculectomy; UK

Patients' narrative accounts, of their illness experience, are a rich resource for understanding, beyond that afforded by clinical examination or formal case history. ${ }^{1}$ Central to these stories are doctor-patient relationships, and it has been suggested that glaucoma specialists' knowledge of patients' subjective attitudes to glaucoma-related issues deserves further investigation. ${ }^{2}$ Medical practice framed in terms of relationships focuses on ongoing doctor-patient interactions, and the everyday concerns of individuals. It is through communication that relational concepts such as partnership, trust, confidence and respect are experienced and observed. But some argue that greater reliance on technology and blueprints for care, such as evidence-based practise and managed care, undermine effective communication by devaluing patients' personal experience and subjective opinions. ${ }^{3}$ Thus, 'physician and patient may meet, but not encounter, speak but not reveal, and hear but not listen. ${ }^{4}$ Therefore, there is a continuing need for research into how health care processes and outcomes are influenced by doctor-patient communication and relationships, particularly in relation to improving outcomes from chronic disease among BME communities.

We explored the perspectives of AfricanCaribbean patients who had undergone trabeculectomy for advanced glaucoma. The sampling was purposive with invitations to participate extended to all African-Caribbean patients $(N=28)$ attending one specialist glaucoma clinic at a regional ophthalmology centre. Eight patients agreed to be interviewed. Collectively they epitomised the key concerns about African-Caribbean glaucoma: early onset, aggressive disease, and low levels of awareness. Qualitative interviews were used to collect the data. Participants were asked to recount when they first became aware of a problem with their eyes and their feelings at the time. Subsequently they were probed about their subjective experiences of becoming a glaucoma patient, 
receiving treatment, the decision to undergo surgery, and its aftermath. The local research ethics committee approved the study.

\section{Transcript analysis}

The universal 'mythic journey' story transcends cultures and recurs frequently as a metaphor in social science and health care disciplines. The data were organised around four stages: 'call to adventure' (being alerted to serious change), 'crossing the first threshold' (accepting the diagnosis of glaucoma), 'trials and ordeals' (facing up to treatment and surgery), 'the road back' (life after surgery). Subplots within these core stories contained powerful images of actions and emotions associated with the impact of the diagnosis and the surgeon-patient relationship. These were analysed further according to the defining features of 'abstract' (what the story is about), 'orientation' (situation and context), 'complicating action' (main account of events), 'evaluation' (highlights point of the story), resolution (outcome), and coda (indicates closure). In describing their experiences the patients established their identity in terms of what they perceived as their duties and obligations towards the relationship with their surgeon. For example, one cast himself as keeper of the bond between himself and the surgeon along the 'rocky road' towards an uncertain future (Box 1); another as compliant and responsible, he was 'grateful', and placed himself in the surgeon's hands. Another was an active only expertise as a surgeon and information source, but also willingness to confirm them as people and individuals.

\section{Comment}

Chronic illness is described as a 'biographical disruption' in which individuals are forced to reassess their selfperception, personal biography, life trajectory and personal relationships. ${ }^{5}$ Self-care and resourcefulness are important dimensions in patients' responses to chronic illness, and the doctor-patient relationship is central to developing effective coping strategies. Our patients' stories are not interpreted simply as 'true' reports on reality. Rather, they are viewed as separately constructed narratives that, as a collection, give deeper insight into the subjective viewpoints of glaucoma patients than could be reached in a single account. By reading each story in light of the others, they form the beginning of a community narrative that gives meaning, understanding, and expression to the experience of African-Caribbean patients in the glaucoma care system.

\section{Acknowledgements}

The following organisations funded the research: Birmingham Strategic Health Authority; Heart of Birmingham Teaching Primary Care Trust; City Hospital NHS Trust; Pfizer UK and Birmingham Social Services.

Box 1 Nathan's story

\begin{tabular}{|c|c|}
\hline $\begin{array}{l}\text { Abstract: what the story is } \\
\text { about }\end{array}$ & Well, it started I had an appointment. \\
\hline $\begin{array}{l}\text { Orientation: establishes } \\
\text { situation, context }\end{array}$ & $\begin{array}{l}\text { Then he said the pressure in my eye was fifty, which is extremely high. And he said, 'Well, } \\
\text { we're going to have to operate to get the pressure down, otherwise I will go blind, within a } \\
\text { few months'. }\end{array}$ \\
\hline $\begin{array}{l}\text { Complication: main account of } \\
\text { events and how these are } \\
\text { made sense of by the narrator }\end{array}$ & $\begin{array}{l}\text { So he asked me would I prefer to have an operation, rather than the eye drops. 'Cos } \\
\text { obviously the eye drops are going to take longer to take down the pressure. So it was a } \\
\text { three-way decision really. It was me, my Mom and the doctors all agreeing at the same } \\
\text { time'. }\end{array}$ \\
\hline $\begin{array}{l}\text { Evaluation: highlights the } \\
\text { point of the story }\end{array}$ & $\begin{array}{l}\text { Yeah, I was in total control really, 'cos if I didn't want to have the operation, then, I wouldn't } \\
\text { have it'. }\end{array}$ \\
\hline $\begin{array}{l}\text { Resolution: outcome, what } \\
\text { finally happened }\end{array}$ & $\begin{array}{l}\text { It's kind of important because, obviously, I mean if I'm not in total control and the doctor's } \\
\text { saying, obviously I need to operate, and obviously, I'm not saying you need to operate then } \\
\text { there's no comparison, there's no bond where the doctor is getting on with the patient. }\end{array}$ \\
\hline Coda: indicating closure & $\begin{array}{l}\text { 'Cos it's like a rocky road, actually. You never know what's going to be at the end, you never } \\
\text { know what's going to happen half way in between. You've got to keep that bond between } \\
\text { you and the specialist at all times'. }\end{array}$ \\
\hline
\end{tabular}

agent in his own destiny, 'So, we did the operation and it could not have gone better.' At the same time, patients also drew attention to what they considered were the surgeon's duties and obligations. These encompassed not

\section{References}

1 Humphrey C. Ways of seeing: biomedical perspectives on the social world. J R Soc Med 2006; 99: 602-606. 
2 Doescher MP, Saver BG, Franks P, Fiscella K. Racial and ethnic disparities in perceptions of physician style and trust. Arch Fam Med 2000; 9: 1156-1163.

3 Hasnain-Wynia R. Is evidence-based medicine patientcentred and is patient-centred care evidence-based? Health Serv Res 2006; 41(1): 1-7.
4 Dietlin TS, Jordan J, Dinslage S. What do glaucoma specialists know about the patients? Graefes Arch Clin Exp Ophthalmol 2005; 244(7): 859-862.

5 Taylor D, Bury M. Chronic illness, expert patients and care transition. Sociol Health Illn 2007; 29(1): $27-45$. 